\title{
Ventilator-Associated Pneumonia in Pediatric Intensive Care Unit: Authors' Reply
}

\author{
Sushil K. Kabra ${ }^{1} \cdot$ Rakesh Lodha $^{1}$
}

Received: 31 March 2015 / Accepted: 9 April 2015 / Published online: 8 May 2015

(C) Dr. K C Chaudhuri Foundation 2015

To the Editor: We thank the authors of the article entitled "Study of ventilator-associated pneumonia in a Pediatric Intensive Care Unit" for the clarifications with respect to their work [1] and our commentary [2]. The clarification regarding the diagnosis of ventilator-associated pneumonia (VAP) is valuable. Similarly, the details about the unit will help readers understand the context. The finding of the low incidence of VAP with the low nurse to patient ratio is commendable.

Conflict of Interest None.

Source of Funding None.

\section{References}

1. Balasubramanian P, Tullu MS. Study of ventilator-associated pneumonia in a pediatric intensive care unit. Indian J Pediatr. 2014;81: 1182-6.

2. Gnanaguru V, Kabra SK, Lodha R. Ventilator-associated pneumonia in pediatric intensive care unit. Indian J Pediatr. 2014;81:1145-6.

Rakesh Lodha

rakesh_lodha@hotmail.com

1 Department of Pediatrics, All India Institute of Medical Sciences, Ansari Nagar, New Delhi 110029, India 